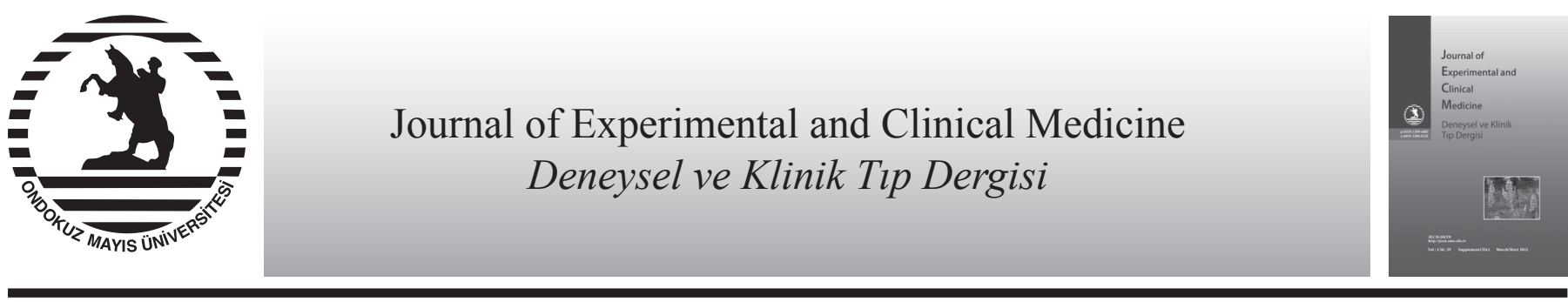

Derleme / Review

doi: $10.5835 /$ jecm.omu.29.s1.003

\title{
Diyabet tedavisinde hasta eğitimi
}

\section{Patient education in treatment of diabetes}

\author{
Gülay Bayrak, Ramis Çolak*
}

Ondokuz Mayıs Üniversitesi, Tıp Fakültesi, Endokrinoloji ve Metabolizma Hastalıkları Bilim Dalı, Samsun, Türkiye

\begin{tabular}{|c|c|}
\hline MAK & GILERİ \\
\hline Maka & \\
\hline Geliş & 13 / $01 / 2011$ \\
\hline Kabul & 15 / 02 / 2011 \\
\hline * Yazı & \\
\hline Ramis & \\
\hline Ondok & Üniversitesi Tıp Fakültes \\
\hline Endok & Metabolizma Hastalıkları \\
\hline Bilim & \\
\hline Kurup & n, Türkiye \\
\hline
\end{tabular}

\begin{tabular}{l}
\hline Anahtar Kelimeler: \\
Diabetes mellitus \\
Diyabet eğitimi \\
Diyabet tedavisi \\
Diyabet komplikasyonları \\
\hline
\end{tabular}

\section{Keywords:}

Diabetes mellitus

Diabetes education

Treatment of diabetes

Diabetes complications

\section{ÖZET}

İyi glisemik kontrolün, önemli mikrovasküler komplikasyonların ortaya çıkışı ve ilerlemesini geciktirmedeki önemi açıktır. İyi kontrole yol açan diyabet tedavisi, diyabetli bireylerin günlük yaşantılarında kendileri tarafından sağlamak zorunda oldukları, 24 saatlik aktivite ve sıklıkla yaşam tarzındaki önemli değişiklikleri içerir. Diyabetin kendi kendine yönetim eğitiminin hedefi sadece diyabet konusunda bilgiyi arttırmak değil, diyabet tedavisini yaşam tarzına katmak için diyabetli bireylerin ve ailelerinin çabalarını desteklemektir. Diyabet eğitimi hastanın yaşam kalitesini artırır, kendi kendine izlem ve tedaviyi iyileştirir, metabolik kontrolü iyileştirir, akut ve kronik komplikasyonların erken tanısını ve önlenmesini sağlar, diyabet için yapılan masrafı azaltır.

J. Exp. Clin. Med., 2012; 29:S7-S11

\begin{abstract}
The importance of improved glycemic control in delaying the onset and progression of serious microvascular complications is now clear. Treatment of diabetes leading to improved control is a 24 hour-a-day activity and often includes important changes in lifestyle, most of which persons with diabetes must provide for themselves on daily basis. The goal of diabetes self management education is not simply to increase knowledge about diabetes, but rather to support individuals with diabetes and their families in their efforts to incorporate diabetes treatment into their lifestyles. Diabetes education improves well being and quality of life of the patient, self-care management and improves metabolic control. Education enhances the prevention and early detection of complications. Education decreases costs of care.
\end{abstract}

J. Exp. Clin. Med., 2012; 29:S7-S11

(C) 2012 OMU
Diyabet, ömür boyu süren akut ve kronik komplikasyonları olan, kişiye, ailesine ve topluma maddi ve manevi yük getiren, yaşam süresini olumsuz etkileyen ve multidisipliner takip edilmesi gereken kronik bir hastalıktır. Bu hastalık insanlığı tehdit etmektedir ve tüm dünyada diyabetik hasta sayısı gittikçe artmaktadır. Bu nedenle şu anda global bir sorun haline gelmiştir.

Dünyadaki diyabetli hasta sayısı 1980 yılında 30 milyon iken, günümüzde bu sayı 280 milyona ulaşmıştır. 2030 yılında ise dünyadaki diyabetli hasta sayısının 430 milyona ulaşacağı hesaplanmaktadır (Unwin, 2010).

Diyabetlilerin, yaşam kalitesinin yükseltilmesi, komplikasyonlardan korunması ve metabolik kontrolün sağlanması için etkili ve sürekli bir bakıma ve izlem programına ihtiyaçları vardır. Bu izlem programında diyabet eğitiminin önemi kaçınılmazdır. Eğitim, diyabetli birey ve ailesi için bakım ve izlemi kolaylaştıracak, devamlılığını sağlayacak bilgi, tutum ve becerilerin tümünü kapsamalıdır.

\section{Diyabet eğitiminde amaç}

Eğitimin esas amacı hastanın diyabete uyumunu kolaylaştırmak, metabolik ve biyokimyasal kontrolü sağlamak, kan basıncını normal sınırlar içinde tutmak ve korumak, ideal vücut ağırlığına ulaşmak ve sağlıklı bir egzersiz programı oluşturmak olmalıdır. Ayrıca diyabetin neden olduğu komplikasyonların gelişimini önlemek ve komplikasyonların yol açtı̆̆ 1 hastalık veya ölümleri engellemektir (Funnel ve ark., 2007). Eğitimin bir diğer amacı da tip 2 diyabetin meydana gelmesini önlemek veya ortaya çıkmasını geciktirmektir.

\section{Diyabet eğitiminin hedefleri}

Diyabetin tedavisinde en önemli hususlardan biri hastanın diyabetin ne olduğunu ve bununla mücadelenin yöntemlerini en iyi şekilde öğrenmesidir. Bu şekilde, kişilerin kendi kendini takip etme becerileri geliştirilir ve günlük yaşamlarında hastalıkları ile ilgili karşılaştıkları tüm sorunların üstesinden 
gelme yeteneği kazandırılmış olur. Dolayısıyla kişi hastalığını yönetmeyi ve tedavisini düzenli uygulamayı öğrenir. Diyabetli hastaların bilmesi gereken hususlar Tablo 1'de gösterilmiştir (Funnel ve ark., 2007).

\section{Tablo 1. Diyabetli hastaların öğrenmesi gerekenler}

1 Diyabet hastalı̆̆ının ne olduğunu

2 Diyabetin tedavi seçeneklerini

3 Diyet tedavisini

$4 \quad$ Fiziksel aktiviteyi

5 Diyabet ilaçları hakkında bilgi ve bunları kullanabilmeyi

6 Kan şekeri ve diğer parametreleri kendi kendine izlemeyi

7 Akut komplikasyonları önlemek, saptamak ve tedavi etmeyi

8 Kronik komplikasyonları önlemek, saptamak ve tedavi etmeyi

9 Karşılaşabilecekleri psikolojik sorunların neler olduğunu

10 Sağlık ve davranış değişikliklerini iyi yönde geliştirebilmek için kişisel stratejilerin ne olduğunu

Gebelik planlayan hastaların gebelik öncesi tedbirlerini,

11 gestasyonel diyabetin ne olduğunu ve gebelik sırasında diyabet tedavisinin nasıl yapıldığını

\section{Tablo 2. Diyabet eğitim ekibi}

1 Doktor

2 Diyabet hemşiresi

3 Diyetisyen

4 Egzersiz fizyoloğu

5 Sosyal hizmet uzmanı

6 Psikolog

7 Göz doktoru

8 Ayak bakım uzmanı

9 Eczac

\section{Tablo 3. Diyabet eğitiminde hedef kitle}

1 Diyabetik hastalar ve bu hastaların aileleri

Sağlık profesyonelleri (Doktor, hemşire diyetisyen), sağlık çalışanları ve diyabetle ilişkisi olan diğer sağlık profesyonelleri.

3 Tip 2 diyabet riski olan kişiler ve bu kişilerin aileleri

4 Medya, işçi ve işveren kuruluşları gibi organizasyonlar

Eğitim sırasında hastalara kan şekeri takiplerini evde devam ettirmeleri gerektiği özellikle vurgulanmalıdır. Bu durum hasta için daha iyi, kolay ve ucuz glisemik kontrol sağlanmasına ve bunun devam ettirilmesine, hipoglisemilerin erken fark edilip önlenmesine yardım eder. Kullanılan tedavinin (insülin ve oral antidiyabetikler) doz ayarını kolaylaştırır ve dolayısıyla daha serbest ve güvenli bir yaşam sağlar. Ayrıca tatil ve spor aktiviteleri daha rahat ve daha güvenli yapılır hale gelir. Ketoasidoz ve hiperglisemik hiperozmolar durum gelişme sıklığını da belirgin olarak azaltır.

Hipoglisemi, ketoasidoz ve hiperglisemik hiperozmolar durum erken fark edilerek önlendiğinden hastaneye yatış sıklığı ve süresi azalır. Daha iyi glisemik kontrolün sağlanması ile uzun dönemde kronik komplikasyonlar az görüleceği için hem yapılan masraf hem de hastaneye yatış sayısı azalır.

Diyabetin kendi kendine yönetimi eğitiminin hedefi sa- dece diyabet konusunda bilgiyi arttırmak değil, diyabet tedavisini yaşam tarzına katmak için diyabetli bireylerin ve ailelerinin çabalarını desteklemektir.

\section{Diyabet eğitimcileri}

Diyabet eğitimcileri, diyabet eğitimi ekip yaklaşımının temelini oluştururlar (Satterfield ve ark., 1986). Ekibin her bir üyesi klinik ve polikliniklerde beraber çalışarak hastalara özel uzmanlık hizmeti sağlarlar. Diyabet eğitim ekibi Tablo 2'de gösterilmiştir. Bu ekibin diyabet eğitimi konusunda sertifikalı olması gerekmektedir.

\section{Diyabet eğitiminde hedef kitle}

Diyabet eğitiminde hasta her zaman eğitimin merkezinde tutulmalı ve eğitim programları buna göre düzenlenmelidir (Tablo 3). Ancak diyabetik hastaların yakınları, bozulmuş glikoz toleransı ve gestasyonel diyabet öyküsü olan yani tip 2 diyabet riski olan kişilerde eğitim programına dahil edilmelidirler. Öte yandan sağlık çalışanları periyodik olarak diyabet konusunda eğitime tabi tutulmalıdırlar.

\section{Diyabet eğitim metodları}

Eğitim stratejileri, durumun gereksinimlerine göre, basit bir telefon irtibatından, kapsamlı bir programa kadar geniş bir yelpazede olabilir. Tek bir eğitim metodu ve materyali yoktur. Hedef kitlenin eğitimi için broşürlerden, telefondan, afişlerden, slaytlardan, kitap veya dergilerden, internetten, görsel ve yazılı medyadan yararlanılabilir. Ancak bunların hiç birisi diyabet eğitimcilerinin birebir vermiş olduğu eğitimin yerini tutmamaktadır.

Diyabetli kişileri eğitmek için farklı yöntemler kullanılmaktadır. Sağlık profesyonellerinin veya diyabet eğitimcilerinin bire bir veya grup eğitimleri yaparak hedef kitleyi eğitmesi en önemli eğitim yöntemidir. Doktorların ve diğer sağlık çalışanlarının diyabetik hastalara yeterli zaman ayırmaları gerekmektedir. Bu eğitimler hasta yatağında, polikliniklerde veya sağlık profesyonellerinin ofislerinde yapılabileceği gibi, hastanede veya hastane dışındaki toplantı salonlarında da yapılabilir.

\section{Diyabet eğitimine başlama zamanı ve süresi}

Diyabet eğitimine anne karnında başlanıp anne ve çocuğun ömrünün sonuna kadar devam edilmelidir. Eğer anne diyabetik ve bu konuda bilinçli değil ise çocuğunda gelişecek olan makrozomi sonraki yıllarda aynı çocukta diyabet gelişimi için çok önemli bir risk faktörüdür. Annenin kan şekeri belirlenen sınırlar içinde tutulursa, makrozomi gelişme riski, diyabeti olmayan annelerin çocuklarınınkine yaklaştırılır. Yani diyabet prevalansını azaltmak için, diyabet eğitimine anne karnında başlanıp anne ve çocuğun ömrünün sonuna kadar devam edilmelidir. Diyabetik kişilerde eğitime ilk tanı konulduğu andan itibaren başlanmalı ve hastanın kişisel özelliklerine, öğrenim ve sosyal durumuna, hastalığının seyrine göre kişiye özel olarak planlanmalıdır. Öte yandan verilen eğitimlerin sürekliliğinin sağlanması da önemlidir. Diyabetli kapsamlı ve planlı bir eğitim programına alındıktan sonra bilgi ve becerileri bilimsel veriler 1 şı̆̆ında düzenli olarak kontrol edilmelidir. Sağlık profesyonellerinin danışmanlık ve eğitim hizmetini eksiksiz sunması aynı zamanda hastanın kendini güvende hissetmesini de sağlar.

Hasta hem emosyonel hem de deneyim olarak hazır olduğunda eğitim başlarsa, hastanın eğitime katılma şansı 
daha fazla olmaktadır (Redman, 1988). Hastanın ruhsal durumunun iyi olması öğrenmeyi kolaylaştırır.

Takip aşamasında da başlangıçtaki detaylı eğitimi tamamlayan hastaların yaşamlarının farklı zamanlarındaki değişen ihtiyaçlarını karşılayabilmeleri için periyodik eğitim güncellemeleri çok önemlidir. Bireyler diyabet yönetiminin yeni yollarını öğrenebilirler, değişen ihtiyaçlarına kendi yönetim programlarını adapte edebilme becerilerini geliştirebilirler ve diyabet tedavisi için mevcut yenilikleri ve yeni kaynakları taniyabilirler.

Eğitim sürekli bir gözden geçirme, planlama, uygulama ve değerlendirme sürecidir. Diyabet eğitimi bireye özgü hale getirilmelidir. Ne öğretilmesi gerektiği ve nasıl öğretilmesi gerektiği kişiden kişiye değişir ve değerlendirilmeler buna göre yapılmalıdır.

\section{Hastanın öğrenmesine etki eden faktörler}

Hastanın öğrenmeye hazır oluşunun (Ruggerio ve ark., 1993) ve diyabete adaptasyon aşamalarının değerlendirilmesine ilaveten sağlık profesyoneli, hastanın diyabet bilgisine bakmadan önce hastanın etnik ya da kültürel geçmişi, işi, sosyoekonomik durumu, sosyal güvence sistemleri, kişilik tipi, sağlık inanışları konusunda bilgi almak zorundadır (Rosenstock, 1985). Öğrenme üzerine etkisi olabilen diğer faktörler, yaş, cinsiyet, okur-yazarlık düzeyi ve eğitim düzeyidir (Walker, 1999). Bu bilgi hastanın anlamasında ve hasta için en yararlı ve uygun tedavi ve eğitim yaklaşımında önemlidir.

Diyabetin kendi kendine yönetimi, diyabet eğitim programının güncel içeriği birey veya bireylerin değerlendirilen gereksinimlerine dayalıdır. Pek çok eğitim programı hastaların öncelikleri ile tanımlanan alanlardan başlar. Eğer hasta hastanede yatıyorsa birkaç günde verilebilir. Ayaktan tedavi edilen hastalarda da birkaç gün veya haftalar alabilir.

\section{Diyabet eğitiminin yararları}

Amerika ve bazı Avrupa ülkelerinde diyabet eğitim programlarına katılmayan hastaların bazı tedavi masrafları sigorta tarafindan ödenmemektedir. Bunun sebebi hasta eğitimi olmaksızın yürütülen diyabet tedavisinin yeterince etkili olmadığının ve hatta tedavi masraflarının arttığının farkına varılmasıdır.

Diyabet konusunda bilinçlendirmenin hem hastalara hem de sağlık çalışanlarına sağladığı yararlar vardır. Her şeyden önce sağlık çalışanlarının işleri daha kolaylaşır. Çünkü hasta sorunun ne olduğunu kolay anlar ve kendi kendine bazı problemleri çözebilir. Diyabet eğitimi hastanın yaşam kalitesini artırır. Kendi kendine izlem ve tedaviyi iyileştirir, metabolik kontrolü iyileştirir, akut ve kronik komplikasyonların erken tanısını ve önlenmesini sağlar, diyabet için yapılan masrafı azaltır.

Yapılan çalışmaların çoğunda diyabetik hastalar eğitildiği zaman metabolik kontrolün daha iyi olduğu gösterilmiştir. Kan şekeri, HbA1c ve lipid düzeylerinin eğitim alan hastalarda daha düşük olduğu iddia edilmektedir. Eğer tıbbi tedavi seçenekleri iyi düzenlenmezse sadece diyabet eğitiminin metabolik kontrol üzerine pozitif etkisinin çok iyi olmadığ da ileri sürülmektedir. (Glasgow ve ark., 1987; Brown, 1988; Norris ve ark., 2002).

Diyabet eğitiminin kronik komplikasyon gelişimi üzerine olumlu etkisi açıktır. Nicolucci ve arkadaşları yaptıkları çalışmada, diyabet eğitimi almayan kişilerde kronik komp- likasyon ortaya çıkma riskini daha yüksek olarak tespit etmişlerdir (Nicolucci ve ark., 1981). Aynı şekilde diyabetik ketoasidoz ve hiperglisemik hiperozmolar durum gibi akut komplikasyon sıklığı da diyabet eğitimi ile bariz bir şekilde azalmaktadır. Hasta ve yakınlarının eğitilerek daha bilinçli hale getirilmesi, hipoglisemi sayısında belirgin azalma sağlayabileceği gibi meydana gelen hipoglisemik atakların hızlı ve etkili bir şekilde tedavisini mümkün kılar.

ABD'de diyabet için bir yılda 174 milyar dolar harcanmaktadır. $\mathrm{Bu}$ para ABD sağlık harcamasının yaklaşık \%9'unu oluşturmaktadır. Yapılan hesaplara göre 2025 yılında dünyadaki sağlık harcamalarının \%13'ü diyabet için yapılacaktır (Ulusal Diyabet, Sindirim ve Böbrek Hastalığı Enstitüsü, 2008). Hem yeni diyabet oluşumunun hem de diyabetin akut ve kronik komplikasyonlarının gelişiminin önlenmesi diyabet için yapılan masrafi azaltacaktır. Yapılan çalışmalarda sadece hastaların eğitilmesi ile hastaneye yatış oranlarının \%27 ile \%38 arasında azaldığı bildirilmektedir (Geller ve ark., 1981; Zaremba ve ark., 1985). Scott ve arkadaşlarının yaptığı bir çalışmada, insülin kullanan 197 diyabetik hasta, diyabet eğitimi alanlar ve almayanlar olarak gruplandırılarak hastaneye yatış açısından değerlendirilmiş. Diyabet eğitimi alan gruptan sadece 9 hasta hastaneye yatarken, diyabet eğitimi almayan gruptan ise 70 hasta hastaneye yattığı tespit edilmiştır (Scott ve ark., 1985). $\mathrm{Bu}$ hastalar hastaneye yatış açısından değerlendirildiğinde diyabet eğitimi alan gruptan sadece 9 hasta hastaneye yatmış, buna karşın diyabet eğitimi almayan gruptan ise 70 hasta hastaneye yatmıştır (Scott ve ark., 1985). Diyabet eğitimi almayanlarda hastaneye yatış sayısının daha fazla olduğu ve bu yönden de yapılan masrafın daha fazla olduğu açık olarak görülmektedir.

Anksiyete, depresyon ve kendine güvensizlik gibi diyabetin psikolojik yüküne bağlı, duyguların kötü kontrol ile ilişkili olduğu gösterilmiştir. Bu tür psikolojik problemleri olanlarda metabolik kontrol parametreleri daha bozuktur (Korhonen ve ark., 1983; Kovacs ve ark. 1996; Lustman ve ark., 1997; Jacobson ve ark., 1998; Weinger ve ark., 2001). $\mathrm{Bu}$ yüzden, uygun düzenlenmiş eğitim programı sadece gerçekleri sergilemekle kalmamalı, aynı zamanda diyabetin emosyonel yanıtlarına da hitap etmelidir.

Ülkemizde 1998 yılında erişkin nüfusunun \%7,2'si diyabetli iken 2010 yılında bu oran \%13,7'ye ulaşmıştır. 12 yılda diyabet prevalansı \%90 oranında artmıştır (Satman ve ark., 2002; Satman ve ark., 2010).

$\mathrm{Bu}$ durum ülkemizde diyabet konusundaki farkındalığın halen çok düşük olduğunu, ya da kişilerin diyabet konusunda duyarsız olduğunu ortaya koymaktadır. Bu da riskli kişilerin ve toplumun eğitiminin, yeni diyabet gelişmesi ile mücadelede ne kadar önemli bir role sahip olduğunu bize açık bir şekilde göstermektedir.

Ülkemizde ve dünyada her geçen gün diyabetik hasta sayısının hızla arttığı gerçeği ile yüz yüze kalmaktayız. Buna karşın hastalığın ortaya çıkması ve hasta sayısındaki hızlı artış önlenebilir. Aslında gelişmiş ve gelişmekte olan bütün ülkeler bu sorun ile başa çıkmaya çalışmaktadır. İleride tip 2 diyabet gelişme riski altında olan kişilerin bu konuda bilinçlendirilmesi çok büyük önem taşımaktadır. Kişilerin tek tek eğitilmesi bu problemin çözümü için yeterli olamaz, bütün toplumun bilinçlendirilmesi gerekmektedir. Bozulmuş glukoz toleransı ve bozulmuş açlık glukozu olan kişilerde yaşam tarzı değişikliği ile birlikte (diyet ve egzersiz programı), bunların diyabet açısından eğitilmesinin yeni diyabet oluşumunu azalttığ , ayrıca hastaların daha fazla kilo 
verdiği ve kan basınçlarının daha da düştüğü bildirilmektedir. Hastalara bu konularda yeterli bilgi verilmez ise yaşam tarzı değişikliğinin başarı şansı azalmaktadır (Balagopal ve ark., 2008). Yeni tip 2 diyabet oluşumunun önlenmesi global diyabet yükünü de belirgin olarak azaltacaktır.

\section{Çocuklarda diyabet eğitimi}

Çocukluk çağı obezitesinin ileri yaşlarda diyabet için çok önemli risk faktörü olduğu bilinmektedir. Ayrıca günümüzde tip 2 diyabet çocuklarda da sıklıkla görülmeye başlamıştır. $\mathrm{Bu}$ nedenle çocuklara doğru beslenmeyi öğreterek obezite ve dolayısıyla tip 2 diyabet sayısı azaltılabilir. Çocukları çok sıkmadan, gerekirse biraz da eğlence katarak, okullarda verilecek diyabet eğitimi çok önemlidir.

Öte yandan mevcut diyabetli olan çocukların da tedavi planlamasının yanında diyabet açısından bilgilerin verilmesi çok yararlı olacaktır. Çocukların eğitimi sırasında büyüklerden farklı yöntemler kullanılmalı, eğitim sıkıcı bir aktivite olmaktan çıkarılmalıdır. Küçük çocuklar diyabet ile ilgili problemlerin üstesinden tek başlarına gelemezler. Bu çocukların ebeveynlerinin ve gerektiğinde diğer aile fertlerinin diyabet konusunda eğitim alması şarttır. Aynı zamanda okula giden diyabetli çocukların öğretmenlerinin de diyabet konusunda mutlaka bilgilendirilmesi gerekmektedir.

\section{Eğitimde diyabet hemşiresinin rolü}

İlk kez 1914 yılında Elliott Joslin diyabet eğitimi ve tedavisinde eğitim hemşirelerinin önemli bir rolü olduğunu bildirmiştir. Ayrıca diyabet ve diyabet eğitimi konusun- da uzman olmanın hemşireler için yeni bir kariyer vaat ettiğini vurgulamıştır (Allen, 2003). Günümüzde hemşirelik mesleğinde çok sayıda uzmanlık alanı mevcuttur, ama ilk kabul edilen uzmanlık alanı diyabet hemşireliği olmuştur.

İnsülinin yaygın olarak kullanılmaya başlanmasından sonra, insülin uygulamasının ve karbonhidrat sayımının öğretilmesinde diyabet hemşireliğinin önemi daha belirgin olmaya başlamıştır. Özellikle pompa tedavisi uygulanan hastaların eğitimindeki önemleri giderek artmaktadır.

Son zamanlarda tip 2 diyabetik hastaların tedavisinde oral antidiyabetik ilaçlar ve insülinden başka tedavi seçenekleri de kullanım alanına girmiştir. Bu tedavi modellerinin nasıl uygulanacağının hastaya anlatılmasında en büyük sorumluluk diyabet hemşiresine aittir. Diyabet hemşiresi hastaya sadece tedavi metotlarının uygulanması ile ilgili bilgilerin yanısıra diyabet hakkında kişilerin bilmesi gereken diğer bilgileri de aktarır.

\section{Sonuç}

Diyabet tüm insanlığ tehdit eden bir sağlık sorunudur ve aynı zamanda kronik bir hastalıktır. Kontrol altına alınamadığında hastalar uzun vadede ortaya çıkan komplikasyonlar ve bunların yol açtığı sağlik sorunlarıyla karşı karşıya kalmaktadırlar. İleri evredeki diyabet ve buna eşlik eden hastalıkların tedavi sürecinde her anlamda zorluklar bulunmaktadır. $\mathrm{Bu}$ da maddi ve manevi kayıpların daha fazla görülmesi anlamına gelir. Bu nedenle diyabetin önlenmesi ve varolan hastalığın ilerleyerek organ hasarı yapmadan kontrol altına alınması her anlamda önem taşımaktadır.

\section{KAYNAKLAR}

Allen, N., 2003. The history of diabetes nursing, 1914-1936. Diabetes Educ. 29, 976-989.

Balagopal, P., Kamalamma, N., Patel, T.G., Misra, R., 2008. A community-based diabetes prevention and management education program in a rural village in India, Diabetes Care 31, 1097-1104.

Brown, S.A., 1988. Effects of educational interventions in diabetes care: A metaanalysis of findings. Nurs. Res. 37, $223-230$.

Funnel, M.M., Brown, T.L., Childs, B.P., Haas, L.B., Hosey, G.M., Jensen, B., Maryniuk, M., Peyrot, M., Piette, J.D., Reader, D., Siminerio, L.M., Weinger, K., Weiss, M.A., 2007. National standarts for diabetes self-management education. Diabetes Care 30, $1630-1637$.

Geller, J., Butler, K., 1981. Study of educational deficitis as the cause of hospital admisson for dibetes mellitus in a community hospital. Diabetes Care 4, 487- 489 .

Glasgow, R.E., McCaul, K.D., Shafer, L.C., 1987. Self-care behaviors and glycemic control in type 1 diabetes. Chronic Dis. 40, $399-412$.

Jacobson, A.M., Wienger, K., 1998. Treating depression in diabetic patients: is there an alternative to medications? Ann. Intern. Med. 129, 656657.

Korhonen, T., Huttunen, J.K., Aro, A., Hentinen, M., Ihalainen, O., Majander, H., Siitonen, O., Uusitupa, M., Pyörälä, K., 1983. A controlled trial on the effects of patient education in the treatment of insulin-dependent diabetes. Diabetes Care 6, 256-261.

Kovacs, M., Mukerji, P., Iyengar, S., Drash, A., 1996. Psychiatric disorders and metabolic control among youths with IDDM: A longitidinal study. Diabetes Care 19, 318-323.

Lustman, P., Griffith, L.S., Clouse, R.E., 1997. Depession in adults with diabetes. Semin. Clin. Neuropsychiatry 2, 15-23.

National Institute of Diabetes and Digestive and Kidney Disease, 2008.

Nicolucci, A., Cavaliere, D., Scorpigline, N., Carinci, F., Capani, F., Tognoni, G., Benedetti, M.M., 1981. A comprehensive assessment of the avoidability of long-term complications of diabetes. Diabetes Care 4, 487-489.

Norris, S.L., Lau, J., Smith, S.J., Schmid, C.H., Engelgau, M.M., 2002. Self-management education for adults with type 2 diabetes: A Metaanalysis of the effect on glycemic control. Diabetes Care 25, 1159-1171.

Redman, B.K., 1988. The process of patient education, 6th ed. St. Louis: Mosby, pp. 21-48.

Rosenstock, I.M., 1985. Understanding and enhancing patient compliance with diabetic regimens. Diabetes Care 8, 610-616.

Ruggerio, L., Prochasca, J.O., 1993. Readiness for change:Introduction. Diabetes Spectrum 6, 22-24.

Satman I, Alagöl F, Ömer B, Kalaca S et all., 2010 TURDEP 2. Çalışma Grubu 32. Türkiye Endokrinoloji ve Metabolizma Hastalıkları Kongresi 13-17 Ekim 2010.

Satman, I., Y1lmaz, T., Sengül, A., Salman, S., Salman, F., Uygur, S., Bastar, I., Tutuncu, Y., Sargin, M., Dinccag, N., Karsidag, K., Kalaca, S., Ozcan, C., King, H., 2002. Population-based study of diabetes and risk characteristics in Turkey: result of the Turkish diabetes epidemiology study. Diabetes Care 25, 1551-1556.

Satterfield, D.W., Davidson, J.K., 1986. The team approach to evulation, education and treatment. In: Davidson JK, ed. Clinical diabetes mellitus: a problem- oriented approach. New York: Thieme, pp. 128-141.

Scott, R.S., Brown, L.J., Clifford, P., 1985. Use of health services by diabetic persons, II hospital admissions. Diabetes Care 8, 43-47.

Unwin, N., Gan, D., Whiting, D., 2010. The IDF Diabetes Atlas: providing evidence, raising awareness and promoting action. Diabetes. Res. 
Clin. Pract. 87. 2-3.

Walker, E.A., 1999. Characteristics of the adult learner. Diabetes Educ. 25, 16-24.

Weinger, K., Jacobson, A.M., 2001. Psychosocial and quality of life correlates of glycemic control during intensive treatment of type 1 diabetes. Patient Educ. Couns. 42, 123-131.

Zaremba, M.M., Willhoite, B., Ra, K., 1985. Self-reported data: Reliability and role in determining program effectiveness. Diabetes Care. 8, 486-490. 